\title{
CLIMATE COLLAPSE, JUDGMENT DAY, AND THE TEMPORAL SUBLIME
}

\author{
TED TOADVINE \\ The Pennsylvania State University
}

It is commonplace today to hear climate change identified as the single most important challenge facing humanity. Consider the headlines from COP24, the United Nations Climate Change Conference held in Poland in December 2018. U.N. Secretary-General António Guterres opened the proceedings by calling climate change "the most important issue we face" (PBS 2018). The Secretary-General's remarks paraphrase the opening line of the U.N.'s climate change web page, which announces that "[c]limate Change is the defining issue of our time and we are at a defining moment" (United Nations n.d.). Such statements about the singular significance of climate change - the most important, the defining issue - are often followed by proclamations about what hangs in the balance, and this was the case at COP24. There, the celebrated British naturalist Sir David Attenborough warned that "collapse of our civilizations and the extinction of much of the natural world is on the horizons," amounting to, in his words, "disaster of global scale, our greatest threat in thousands of years" (Jordans and Scislowska 2018).

As common as this rhetoric is, and despite the important strategic role that it plays in the context of international climate negotiations, it leaves me profoundly uneasy. I say "uneasy," rather than "skeptical," because I am neither a skeptic about anthropogenic climate disruption nor about the scientific evidence and predictions of terrible times to come. What leaves me uneasy is something else, a matter of how the present is interpreted when climate collapse is identified as the most important issue we face, threatening the collapse of civilization as such. This suggests, first, that civilization has been going along just fine and would continue to do so if not interrupted by something more or less external to it, something not essential to it or to its continuation. We are called to marshal all available resources as quickly as possible to address the single greatest challenge the world has ever faced, in the hopes that we can preserve it in its present form, sustain it, into the future as far as possible. I am uneasy with this assessment of our present state of affairs and this emergency prioritization of its continuation as the decisive issue of our time. 
Second, I am uneasy about the "we" who here claim to speak for humanity, for "our civilizations." How much of humanity does this "we" include? Would the ten percent of the world's population living in extreme poverty today, or the nearly half of the world's population that struggles to meet basic needs, agree that climate collapse is the most important issue "we" face? (World Bank 2018). Would those whose lives, livelihoods, and communities have been violated by extractive industries, by settler colonialism, by forced migration, by environmental injustices, by police violence, by anti-Black racism, by the intersections of violence and oppression that have made and continue to make "our" civilization possible - would they agree that climate change is "the defining issue of our time" or that every available resource should be mobilized to maintain the world in its present form? This is far from obvious to me.

To be clear, I do not believe that anyone will be better off as a consequence of climate disruption. It is well-established that the most vulnerable - the poor, women, children, the elderly, communities of color, the displaced, the incarcerated - will suffer the most. And even the wealthiest and most privileged will be unable to avoid its effects entirely. ${ }^{1}$ In this sense, it could be considered a common danger, a danger shared by everyone. Some see in this a reason for political optimism. Traditionally, communities of color have been "our" environmental sacrifice zones, the dumping grounds for extractive and polluting industries, incinerators, toxic waste, and so on, so that the costs of "civilization" could remain out of sight and out of mind for those who accrue its benefits. But climate change is happening to everyone, and the violence of the extractive industries that feed it is already impacting educated, wealthy, white communities, so that new coalitions have become possible. ${ }^{2}$ Those with political and economic clout, or at least some of them, are now motivated to address the root causes of climate change since they can no longer avoid its effects. But this is precisely why the "we" rings hollow when it declares climate change the decisive issue for everyone, rather than for those who are most invested in the continuation of the world as it is.

I have started here intentionally with my feelings of uneasiness, rather than with any argument per se, because I do not dismiss the genuine hardships to come. As of December 2020, the last seven years have been the hottest years since we began keeping records. Real human lives have been lost as a result, and this is still the beginning. And so it is difficult to bring the rhetoric of urgency surrounding climate destabilization into critical focus. Nevertheless, it is precisely this rhetoric of urgency that is my topic here.

We begin, then, by asking whether this prioritization of climate destabilization as the defining threat of recorded human history is justified. In his book, Stolen Future, Broken Present, David Collings (2014) suggests that climate disruption deserves this status because it fundamentally alters our relationship to the future as such. As he describes in a chapter titled, "The Ruins to Come," climate predictions portray our present culture and lives,

\footnotetext{
${ }^{1}$ See Collings (2014), especially chapter 1.

2 This is roughly Naomi Klein's (2014) argument in This Changes Everything.
} 
the world of today, as future ruins. Looking around us right now, we should see this world shadowed by the ruin it is on the verge of becoming. Still, this is not enough to make climate collapse the definitive danger of human history: civilizations have ended before, and we have all admired the picturesque ruins that they have left behind. And certainly, at various points, those whose civilizations were in decline had premonitions of what was coming and could also picture their own worlds as future ruins. But there is more. The future ruins of climate change are not confined to a few buildings, or a city, or a landscape. This time, the future ruins encompass the earth as a whole (105). Before, we might have said that, while civilizations rise and fall, nature endures. This is no longer true. Before, those whose cultures were collapsing might still have had hope in a different future for themselves or their children, the possibility to rebuild elsewhere. But this time, survivors will witness the definitive eclipse of humanity's future, with no guarantees of any new beginning (107). As Collings (2014) concludes:

Our own mortality fades in comparison to something altogether more harrowing - the possible mortality of our societies, the natural systems we know, and to some extent the biosphere itself. In our world, the temporal coherence of a future into which our individual lives vanish - the coherence, in short, of mortality itself - is falling into decay. (112)

At stake in climate disruption, then, is not merely the ruin of $a$ world, that of the civilizations of today, but of the very basis for the world and even for time itself as we know it.

Collings is not alone to see the ruins of the future in the figure of climate disruption. For Andrew Benjamin (2017), in an essay titled "The World in Ruins," it is the task of philosophy to think the end of the world starting from a double sense of catastrophe. A catastrophe in the first and transformative sense would decouple the existing link between climate change and injustice, thereby bringing about the creation of a new world (102-03). But such a transformative catastrophe may no longer be a possibility for us today. In that case, we are left only with the second sense of catastrophe, catastrophic climate change, without transformation or continuity. As Benjamin writes, "[ $t]$ he end to be thought is the end of the world as such, that is, a world that is now present without always already bearing within it the inscription, image, or possibility of another beginning" (103). It is this "ending without a beginning . . . an ending that is not itself a preparation for a beginning," whose insistence demands thought $(104,109)$.

Framing Benjamin's inquiry is the conviction that philosophy can no longer remain apathetic to its own predicament, that it is no longer possible to refuse, on philosophical grounds, the relation between philosophy and the now in which it takes a stand (101-02). By "the now," italicized to distinguish it from our simple sense of now, he intends "a thinking of the present as that which generates the philosophical task" (118 n. 1). The insistent now of such a philosophical task would be entirely distinct from either the self-evident now of empiricism or the inevitable now of naturalism. With this redefinition of philosophy's task, Benjamin takes us a long way toward articulating an essential aim of critical phenomenology, which, in taking a stand, would "allow the question of its own stand in relation to the now 
to delimit a specific philosophical project." Benjamin's (2017) own contention here is that "what determines or defines the now is the ineliminable presence of catastrophic climate change, a change that is leaving the world in ruins" (102). In short, where philosophy stands now can only be thought in relation to this predicament, so that, as he succinctly puts it, "what has to be thought is the end of the world" (101).

Here I take up this task of thinking the now in its relation to the future, or to the end of the future. But I do so by asking after the image of time that this orientation toward the end implies or unfolds. More precisely, my starting point will be popular narratives of climate change, and environmentalism more generally, with respect to their apocalyptic structure. Apocalyptic fantasies weave through contemporary culture and intertwine themselves with our scientific predictions and our efforts to manage the future. I propose that these apocalyptic fantasies enact a temporal narrative that first became possible with our discovery of "deep" geological timescales, scales of time so vast that they explode all efforts to integrate them with the time of human life. The emergence of secular apocalyptic narratives goes hand-in-hand with this expansion of the horizons of time, so that time encompasses pasts that precede us as well as futures that survive us. In short, a radical end of the world first becomes thinkable through a new image of time, a new temporal sublime, that underlies apocalypticism in its recent forms, including speculative fictions, nuclear fears, environmental disaster, and climate disruption.

On this basis, I explore a series of questions posed by such apocalyptic narratives: Does this image of time exhaust our possibilities for relating to the sublime dimensions of the deep past and far future? Does it skew our relation to the present, to the now? What investments or fears are expressed through this apocalyptic image, and what does it reveal about our responsiveness to and responsibility for the past, present, and future? Does justice demand of us a different image of time, and what form might this take?

I proceed first by briefly summarizing the transformation of temporal horizons opened by geological scales of time and past extinctions as a reconfiguration of the temporal sublime. I turn then to the role of apocalyptic narratives in climate change rhetoric and the image of time that frames these narratives. Here, I am especially interested in the role that crisis plays as the passage from the corrupt present to a purified future, marked by the transfiguration of time in the crucible of Judgment Day. On this basis, I consider some of the investments and motivations underlying the tragic and comic modes of time that drive climate narratives. I argue that these instantiate what Jean-Luc Nancy has called "catastrophic equivalence," leveling time into homogenous and substitutable units to facilitate the predictability and manageability of the future. Rather than owning our temporal responsibilities, then, apocalyptic narratives in fact seek to liquidate our obligations to the past, obscure the singularity of the present, and exert absolute control over the future. A just image of time faces two demands: responsiveness to the singularity of the present, and to the entanglement of this present in the plexities of past and future. I conclude with two explorations of this figure of temporal justice: Kyle Powys Whyte's (2018) proposal of "spiraling time" as a living dialogue with our ancestors and descendants, and artist Roni Horn's installation, Library of Water, in Stykkishólmur, Iceland. 


\section{THE TEMPORAL SUBLIME}

I begin with some historical context for our shifting horizons of time, which I read through the lens of the temporal sublime. The fact that long expanses of time confront the human mind with a sublime dimension was recognized by both David Hume and Immanuel Kant, although neither devotes much attention to this experience. ${ }^{3}$ Kant's entire treatment of this topic in his pre-critical Observations on the Feeling of the Beautiful and the Sublime [1764], for instance, appears in the following few lines:

A long duration is sublime. If it is of time past, it is noble; if it is projected forth into an unforeseeable future, then there is something terrifying in it. An edifice from the most distant antiquity is worthy of honor. Haller's description of the future eternity inspires a mild horror, and of the past, a transfixed admiration. $(2007,26)$

In the later terms of the Critique of Fudgment [1790], this suggests that the past confronts us with an experience of the mathematical sublime, and indeed Kant refers there to past time as an infinite magnitude $(1987,111)$, although this later text offers no further mention of time's sublime character. The unforeseeable future, on the other hand, although never mentioned in the Critique of Fudgment, would be a species of the dynamically sublime, arousing fear in us in a way that is somehow parallel to the elemental examples that Kant favors: threatening rocks, thunderclouds, volcanoes, hurricanes, and the like (120). ${ }^{4}$ The reference here to Albrecht von Haller's (2002) "Uncompleted Poem on Eternity" suggests that, for Kant, the future is not to be thought as an infinite magnitude since it is progressing towards its end. And, indeed, he returns to Haller in his 1794 text, "The End of All Things" - a rebuke of Prussian millenarian politics - where what is at stake is not a future proceeding to infinity but precisely eternity as the horrifying abyss that opens beyond the edge of time, beyond the Judgment Day that brings the sensible world to its conclusion. Eternity beyond time is unthinkable, and its "frighteningly sublime" character is due in part to its obscurity; yet, according to Kant, "in the end it must also be woven in a wondrous way into universal human reason, because it is encountered among all reasoning peoples at all times, clothed in one way or another" (1996, 221; emphasis in original). The caution of Kant's tale is to remember that the religious and cultural imagery with which we clothe this notion of eternity must be understood according to the moral order and not in literal or physical terms.

${ }^{3}$ Hume (2007, 274-80); Kant (2007); Brady (2013) traces some of the early history of the temporal sublime.

${ }^{4}$ Such elemental examples of the dynamically sublime are also among the omens for Judgment Day (Kant 1996, 225). 
For both Hume and Kant, the sublime past is revealed only through cultural antiquities, never through natural or elemental phenomena. ${ }^{5}$ But in the thirty years that separate these sparse references to the temporal sublime in Kant, developments in what would come to be known as geological science were setting the stage for a dramatic reorientation in our relationship with long durations of time. James Hutton's 1788 Theory of the Earth famously proposed a concept of geological time with "no vestige of a beginning - no prospect of an end" (304), and through the writings of his friend and popularizer, John Playfair, this newly opened horizon of what would come to be known as "deep" time was characterized from the outset in sublime terms. ${ }^{6}$ This discovery of the deep past simultaneously opens the horizons of the far future and our contemporary cultural obsession with apocalypse. Georges Cuvier's evidence for prehistoric extinctions laid the groundwork for Mary Shelley's exploration of future human extinction in her 1826 novel, The Last Man, generally recognized as the first secular apocalyptic novel. The genre of apocalyptic speculative fiction inaugurated by Shelley first gained popularity by imagining our demise from natural causes, but the First World War shifted our fantasies toward the prospect of self-annihilation by weapons of mass destruction. And Rachel Carson's Silent Spring, written during the lead up to the Cuban Missile Crisis, played a key role in transferring our nuclear anxieties to the emerging threat of ecological collapse.

Contemporary climate apocalypticism is therefore simply the latest phase in our cultural efforts to manage the sublime dimensions of our uncertain future. Just as the threat of total nuclear war - what Jacques Derrida in 1984 termed the "phantasm of a remainderless destruction" (2007, 396) - framed human reality during the Cold War period, so the phantasm of future climate collapse constructs our present today. Ongoing debates over whether to name our contemporary geological period the "Anthropocene" are symptomatic of this transfigured temporal perspective, which offers a vantage from which humanity can hold itself responsible - for the first time - for our long-term ecological transformations of the globe, while raising - also for the first time - the question of our ethical obligations toward an unimaginably distant future. At stake, then, in environmentalism's adoption of apocalyptic narratives is an underlying image of time, one that becomes especially salient in climate change narratives. Let us consider, first, the reliance of climate discourse on apocalyptic narratives and then draw out the image of time by which these are framed.

\footnotetext{
${ }^{5}$ In Critique of Fudgment, Kant (1987) points out that the shape of land and sea as encountered today is the result of chaotic upheavals and disturbances in ancient times, recorded in the "memorials of mighty devastations" studied by the "archeology of nature" (or "theory of the earth"). But Kant does not discuss these "memorials" as having a sublime character due to their antiquity, and they do not pre-date "man"; the lack of human fossil remains is explained, for Kant, by the fact that "his understanding was able to rescue him (for the most part, at least) from those devastations" (316).

${ }^{6}$ See, in particular, Playfair's (1822( description of his 1788 trip with Hutton to Siccar Point (80-81).
} 


\section{CLIMATE COLLAPSE AS JUDGMENT DAY}

During the final week of the 2009 United Nations Climate Change Conference, four Greenpeace activists paraded on horseback through the streets of Copenhagen dressed in costumes representing famine, pestilence, war, and death. Invoking the four horsemen of the apocalypse from the biblical Book of Revelations, their intent was to dramatize the stakes of climate change negotiations. In a press release from Greenpeace International, Sini Harkka of Greenpeace Nordic explained that " $\mathrm{t}]$ he spectre of the four horseman is looming over these climate negotiations ... Yet world leaders are still failing to grasp the urgency of the crisis" (Greenpeace International 2009). Despite the drama of this example, such uses of apocalyptic rhetoric to influence public opinion and political will concerning climate change no longer surprise anyone, and there has been considerable debate among scholars and activists about whether this rhetoric actually achieves its desired effect. These debates tend to start from an understanding of "apocalypse" as straightforwardly synonymous with catastrophe, with the end of the world "as we know it," whether that means the end of "our" current standard of living, or the end of human civilization in any historically recognizable form, or the literal extinction of the human species, and so on. And when apocalypse is read as synonymous with catastrophe, the rhetorical deployment of the narrative is understood to be in the service of galvanizing individual action and political will through fear and horror at the likely consequences of inaction. This rhetorical strategy can then be criticized as ineffectual or counter-productive fear-mongering along the lines familiar from Ted Nordhaus and Michael Shellenberger (2007).

Now, my interest here is not with the psychological or political efficacy of apocalyptic rhetoric, but with the temporality that it enacts. To that end, I want to call attention to the trend, noted by Stefan Skrimshire (2014), of stripping references to apocalypse of their "theological nuances" in favor of their "sensationalist elements," and particularly of treating such discourses as reducible to fear of the future. What is obscured here, Skrimshire reminds us, is precisely the "complex dramatic structure" of the religious apocalyptic narrative, which includes "the creation of tension between the corruption that is endured in the present age and the hope in the new age that is yet to come" (237). The temporal, eschatological element of apocalyptic thinking is precisely to be found in this productive tension, which revolves around an explicit or implicit "Judgment Day."

One of the defining features of apocalyptic temporality is said to be its linear directionality, either guided by divine providence or driven by natural forces, toward a catastrophic endpoint, a "judgment day," beyond which all individual human judgment is irrelevant (Foust and Murphy 2009, 154). Alongside the spectacular destruction of the current world, this narrative structure "prophecies (directly or implicitly) a new world order," and Judgment Day marks the passage into this new age, which is therefore also a new time (154, citing Brummett 1984). To clarify the role of this moment of crisis as a temporal hinge, as the turning point between "our" time and a time to come, we draw on the work of political theorist Ben Jones (2017), who examines the appeal of Christian apocalyptic thinking for 
secular political theorists. Jones focuses on the strand of Christian thinking that he terms "cataclysmic apocalyptic thought," exemplified by the Book of Revelation among other texts, that "identifies crisis as the path to the ideal society" (2). On this view, crisis is not to be avoided but rather welcomed since it is the only path that can wipe away the current state of corruption and replace it with lasting utopia (3). The truly apocalyptic crisis, then, is the final crisis, the one that installs us in a time beyond all crises. And this leavens our everyday struggles, here and now, with transcendent significance, insofar as they are moments of the larger progression toward final purification; we may be losing the local struggle, but we are still on the winning side of the cosmic battle. ${ }^{7}$ My suggestion is that our cultural fascination with fictional apocalyptic narratives is less a manifestation of our desire for our own destruction than our yearning for this transcendent significance; we are ready, in our heart of hearts, to wipe the world away and start again, even at the risk that we might be wiped away with it. In the Christian version of this narrative, of course, the crisis and its aftermath unfold under the guidance of divine providence, and we need only have faith in this. Secular versions proceed without this safety net or try, like Marxism, to replace it by other mechanisms. In any case, the way that we live the apocalyptic narrative today is through our deep pleasure at the prospect of leaping into an unimaginable world and a new age without any guarantees of survival - and, importantly, without any unpaid debts to the past.

The radicality of this image of time follows from the unique moment of judgment, which is precisely a singular break where time folds, dehiscing into the old that is washed away and the ideal future to come. This returns us to Kant's (1996) late essay, "The End of All Things," where he calls attention to the strange temporality of Judgment Day as the hinge between time and eternity, which both horrifies and attracts us with the full force of the sublime. For Kant this is a transition between the happening of events under the conditions of time, on the one hand, and an eternity in which nothing can come to pass, on the other, a situation that cannot be rationally comprehended but is to be understood according to the moral order of ends. Judgment Day is always a selection, a differentiation of the corrupt from the pure, that represents an absolute break with the past - toward which no further debts are owed - and entrance into a finality beyond which no further beginning, no future as such, is possible. What contemporary apocalyptic thinking retains from this structure is the linear sorting of time into a corrupt present and an ideal beyond, with the moment of judgment as their transition. As with Kant, it is the eternal or the utopian moment that remains sublime, unthinkable - and transcendent.

${ }^{7}$ On this point, see Jones $(2017,5)$ and Skrimshire (2014, 239). 


\section{APOCALYPTIC EQUIVALENCE AND TEMPORAL LIABILITY}

The suggestion I have been developing here is that our contemporary apocalypticism remains fundamentally eschatological, that it embraces crisis as a Judgment Day that marks the hinge between our corrupt present world and a new dawn, even or especially when this eschatological frame is not consciously or explicitly theological. It is this basic narrative that has underwritten environmentalism since at least Silent Spring, despite the modifications that it has undergone in the light of new technologies and shifting political contexts. ${ }^{8}$ This narrative justifies itself in terms of our ethical obligations toward the future, and yet it assumes a figure of time that conceals our ethical obligations - not only toward the future, but also toward the past and present.

To see why this is so, we must first recognize that the apocalyptic image of time participates in what Jean-Luc Nancy (2015) has termed the "equivalence of catastrophes." Nancy describes our global ecotechnical situation as an ever-expanding entanglement of interdependencies between innumerable systems - political, military, industrial, financial, logical, natural, and so on. This interdependence depends on the translatability of units across all of these systems, which requires that the units have a common denominator, a common measure of equivalence. This is most obvious in the equivalence of bits and bytes, such as when a picture taken on your phone is stamped with GIS location data, sent by wifi to the cloud, distributed across social media platforms, viewed around the world, backed up on Google's hard drives, added to law enforcement facial recognition databases, and so on. The interdependence of all systems means that our catastrophes, such as the 2011 disaster at the Fukushima Daiichi Nuclear Power Plant discussed by Nancy, are uncontainable in their effects. But the deeper catastrophe, as Nancy argues, is the general equivalence that makes the interdependence of systems possible in the first place, namely, the leveling of all measures into a common denominator that facilitates translation across domains. This general equivalence inspires a proliferation of means and ends without orientation toward any final end or ultimate goal other than their own continued expansion and proliferation. It is this loss of any ultimate sense or direction that Nancy has called the "end of the world" (1997, 4-5). Our constant awareness of the possibility of our own self-destruction stands in place of any final end as the secret fulfillment of the leveling of time into a homogenous continuum $(2015,17-20)$. The operations of this catastrophe of equivalence can be traced in those approaches to sustainability that extrapolate from deep-past trends to predict and manage far-future scenarios, thereby tacitly assuming that our obligation toward the future is to "sustain" the world in a state that resembles as closely as possible our present.

Nancy points out that the absence of any end or goal for our ecotechnical interdependencies apart from their own self-perpetuation traps us in a cycle of planning and management of the future in general, and the extrapolation of the past to calculate

${ }^{8}$ See Killingsworth and Palmer (1996); Buell (2010). 
the future demonstrates the sway of this general equivalence in our understanding of time, since each chronological present moment is substitutable and exchangeable for every other. Now, this catastrophic leveling of time is precisely a means of repressing the sublime dimensions of the future through calculative management. In other words, by leveling time into homogenous and exchangeable units, we defang the future of its unpredictability; we contain it as an infinitely repeatable present. Thus managed, the threat of our extinction or of the end of the world can be indefinitely deferred. On this approach, the threat of the end of the world (and the end of time) justifies absolute management of the world through the homogenization of time. Judgment Day, as the only decisive interruption of the linear and calculable equivalence of "nows," always looms on the horizon as the absolute danger demanding further ecotechnical interdependency, further integration of substitutable systems. This firm grip on managing the future inevitably see-saws into resignation, into the realization that Judgment Day cannot be indefinitely deferred. But this resignation satisfies another deep desire, namely the complete liquidation of the past, a wiping clean of the slate of past debts and obligations. As a repression of the temporal sublime, Judgment Day is both the specter that drives the proliferation of catastrophic equivalence and its consequence.

To make this diagnosis more concrete, we can turn to Potawatomi scholar Kyle Powys Whyte's (2018) critique of settler environmental rhetoric surrounding the Anthropocene and apocalypticism more generally. Whyte notes that settler apocalyptic narratives, proposed as the effort of stopping "a dreaded future movement from stability to crisis," erase the legacies of colonial violence that have been experienced by many Indigenous people as repeated and ongoing apocalypses (227). As Anishinaabe scholar Lawrence Gross (2014) writes, "Native Americans have seen the ends of their respective worlds. . . . Indians survived the apocalypse" (233). Drawing on the work of Tahltan scholar Candis Callison, Whyte notes that "the hardships many nonIndigenous people dread most of the climate crisis are ones that Indigenous people have endured already due to different forms of colonialism: ecosystem collapse, species loss, economic crash, drastic relocation, and cultural disintegration" (226). Furthermore, by seeking to liquidate the past and the present in a new beginning, the settler apocalyptic narrative imagines for itself an innocent future, one in which all obligations and debts for past and present colonial violence are assumed to be discharged. While Whyte's discussion here concerns the experience of Indigenous Americans specifically, his critique of settler colonialism can easily be extended to the historically linked legacy of enslavement. Historian Gerald Horne (2018) writes that " $[\mathrm{w}]$ hat is euphemistically referred to as 'modernity' is marked with the indelible stain of what might be termed the Three Horsemen of the Apocalypse: Slavery, White Supremacy, and Capitalism" (9). Such considerations trouble the ubiquitous narratives that, from some quarters, announce climate change as the apocalypse to come while turning a blind eye to the past and continuing violence that has made the present world a possibility. How might different narratives, guided by a different image of time, do justice to these experiences? 


\section{THE DEEP TEMPORAL SUBLIME AND THE SINGULAR PRESENT}

Breaking with the apocalyptic image of time requires, first, that we come to terms with the plexity of deep time, and second, that we rediscover the singularity of the unique and non-substitutable present. On the first point, the explosion of our temporal horizons far beyond the limits of human history considered by Hume or Kant, and the parallel opening of a deep temporal future that continues beyond human extinction, confront us with the fact that our personal and historical temporalities are entangled and shot through with anachronistic and incompossible durations - those of our evolutionary history, for example, and, further still, of our own elemental materiality. Michel Serres (2018), explaining what he calls the Grand Narrative, the topologically folded multiplex of temporal scales, writes the following: "The senses open the body on to the world, it is said; no, they make us descend into an immemorial duration, towards long lost environments" (12). The experience of the deep temporal sublime is characterized precisely by its incommensurability with the narrative structures of personal and cultural history, by the vertigo of losing all common markers and measures. This testifies to our entanglement in a past that was never our own possibility, never our own memory - an impossible and immemorial past. Indeed, the very "depth" of geological time is the bottomless free-fall into which it throws all markers and touchstones by which we orient ourselves within the temporal horizons of our world. The schema of general equivalence is our unsuccessful attempt to repress this abyssal vertigo.

If we give up the effort to regiment time within general equivalence, then we open ourselves to our ongoing involvement, both material and symbolic, in time's incommensurable vectors and scales: cosmic, geological, elemental, organic, evolutionary. As Serres writes, "[i]nsofar as I am a memory, I participate in things. Insofar as they are things, they have memory" (32). The encounter with the vertigo of deep time is thus the echo within us of evolutionary memory and the asubjective time of matter, which anachronistically interrupt our lived experiences of time from within. A full accounting of the temporal sublime would therefore recognize the confluence of the immemorial past and future in its cosmic, geological, evolutionary, and organic trajectories as a tangle of rhythms, durations, and memories. This takes us well beyond an image of time as linear or metrical; it is instead multiple, folded, percolating. In Serres's words, time flows "according to an extraordinarily complex mixture, as though it reflected stopping points, ruptures, deep wells, chimneys of thunderous acceleration, rendings, gaps - all sown at random, at least in a visible disorder" (Serres and Latour 1995, 57). Because of this non-linear plexity, what seems closest to us chronologically may in fact be distant, while often what we believe to be out-of-date is fully contemporary.

Doing justice to our entanglement in a chaotic multiplicity of durations and memories means breaking with the homogenous leveling of time into substitutable and homogenous units, what, following Nancy, we have called its catastrophic equivalence. To break with this leveling of time requires recognizing the non-equivalence of the unique and non-substitutable events and moments that compose our lives, moments that cannot be exchanged precisely 
because of theirentanglementintheplexities of thepastandfuture. Torecognize thissingularity of every moment deepens our respect for the present, understood not as an immediate or ephemeral "now," but rather as the time of manifestation in which someone or something, always singular and incommensurable, presents itself. The singularity of what appears in the non-substitutable present demands from us an attention and respect, an esteem for the inestimable (Nancy 2015, 39-40). Wendell Berry (2015), the leading proponent of agrarian ideals in the United States, expresses what may be a parallel sentiment when he writes that:

[w] e are always ready to set aside our present life, even our present happiness, to peruse the menu of future exterminations. If the future is threatened by the present, which it undoubtedly is, then the present is more threatened, and often is annihilated, by the future. $(174)$

Nancy (2017) sometimes speaks about the moment of presence as an interruption or suspension of continuity, a deferral of time's self-presentation, in favor of a relationship that demands a gesture or a response (119-21). Yet we see that what presents itself to us, what demands our esteem and our response here and now, may itself be of the past or of the future. A recovery of the present outside the calculable general equivalence of time also places us in an entirely different relationship to pasts that have created our present possibilities and to futures that we do not plan or project. ${ }^{9}$ Responsibility to the present therefore already involves us in the demands of justice for the past and the future. How might we work with such an image of time responsibly in the era of climate change?

For one profound example of how such temporal justice might be enacted we can turn again to the work of Whyte. In contrast with settler narratives of "finality and last-ness," Whyte (2018) describes Indigenous experiences of "spiraling time" that maintain a continuous dialogue with one's ancestors and descendants (229, emphasis in original). Whyte's account situates these experiences of time within specific Indigenous cultural contexts, yet he also invites non-Indigenous allies to engage in "counterfactual dialogue" and critical reflection on how the world that we inhabit today - that is, the world of colonial violence as well as climate change - is the dream and the gift of our settler ancestors, designed and constructed to "fulfill their fantasies of the future" and to "provide privileges to their descendants" (229; 237). Acknowledging that we are living the fantasy of our ancestors simultaneously opens a dialogue with our descendants, who pose to us the question of what kind of ancestors we ourselves will be, and what kind of world we will leave to those who follow. Counterfactual or fictional dialogue operates here not as an escape from our responsibilities to past and future, as we have seen in apocalyptic narratives, but rather as active affirmation of a spiraling of time that binds the manifestive present to the past that conditions it and the futures that it makes possible or forecloses. In contrast with the calculative management of

${ }^{9}$ On the need to break from finality itself, i.e., "from aiming, from planning, and projecting a future in general" and instead to work with "other futures," see Nancy $(2015,37)$. On our ongoing responsibility to "watch out" for the future, see Nancy $(2015,64$ n. 4). On the past that is constitutive of our present possibilities, see Wood (2017) on "Constitutive Time" and Toadvine (2014). 
the future on the basis of the substitutability of homogenous times, and the linear finality of a Judgment Day that liquidates both past and future, such time spiraling interrupts and thickens the event of the present, in its inestimable singularity, with an anti-apocalyptic and anti-colonial figure of temporal justice.

I close with one final example of how we might think the now in an anti-apocalyptic mode, in this case through the work of art. Library of Water is a long-term installation by New York-based artist Roni Horn that occupies a former municipal library in the small town of Stykkishólmur on the southwest coast of Iceland. The building is situated on a high rock promontory overlooking Breidafjordur bay, where its expansive windows reflect the meeting point of earth, sky, and water. Horn has described this space, which hosts community activities as well as private contemplation, as "a lighthouse in which the viewer becomes the light" (Artangel 2007). The central installation, titled "Water, Selected," consists of 24 floor-to-ceiling glass columns, each of which contains water collected from the ice of one of Iceland's major glaciers. Unsurprisingly, these glaciers are retreating at the fastest recorded rates, and one of those represented in the installation - Okjökull - is now classified as "dead" by glaciologists due to climate disruption. The glass columns reflect and refract light from the windows, from each other, and from visitors as they move through their irregular arrangement. The floor on which they stand is embedded with words in Icelandic and English representing the weather. Since each glacier has a distinctive chemical and mineral content, no two columns are identical, and each displays a unique footprint of sediments. With proper names representing the glaciers from which they were drawn, these columns face the visitor like clustering and dispersed figures, solitary yet interacting through plays of light mediated by water and glass. As Janet Fiskio has observed, the glass of each column echoes the ice of the glaciers without any pretense of representation or substitution. ${ }^{10}$ These are not the glaciers themselves, in their varying states of precarity, but precisely their absence, the library and archive of their present and future memory. They are the future ruins of the Icelandic landscape and simultaneously a counter-Narcissus that involves the viewer in their predicament. The work thereby conveys, on the one hand, the excess of the glaciers beyond any possible preservation or representation; their elemental duration cannot be encompassed by any human world. And, on their other hand, it reveals their entanglement in a history and culture that ultimately threatens their disappearance.

Like the spiraling time that Whyte describes, Library of Water binds our singular present to a non-substitutable past and future, now at a grander temporal scale. The glacial water remembers annual snowfalls over the course of millennia, gradually compressed into solid ice by the pressure of patient accumulation. The disappearance of a glacier is literally the liquidation of this past. The proper names of the glaciers reflect their role in the history and culture of Iceland; current rates of glacial retreat have been compared with their historical extent by tracing the journeys recorded in the tenth and eleventh-century Icelandic Sagas. By naming the installation a library, Horn gestures to the indefinite future for which these

10 Personal communication with the author. 
memories are preserved. Furthermore, the multilingual terms for weather embedded in the floor also remind us of our temporality: Serres observes that " $\mathrm{t}]$ he French language in its wisdom uses the same word for weather and time, le temps. At a profound level they are the same thing" (Serres and Latour 1995, 58).

My aim here has been to consider what image of time might break with the apocalyptic narratives that structure our approach to climate change. This requires first coming to terms with the folded, nonlinear, incommensurable, and rich multiplicity of time. As Serres points out, none of the European tradition's great thinkers of time-Bergson, Husserl, Heidegger - ever completed a transatlantic flight $(2018,11)$. But does not the mundane experience of jetlag teach us something about our corporeal entanglement in the plexities of time that would be difficult to learn in any other way? Furthermore, we must break with the catastrophic equivalence that homogenizes the singular moments of our lives, the present in which something inestimable, incalculable, presents itself to us and demands our response. How are we to live in the heartbreaking present? One example is provided in Whyte's account of spiraling time. This is an example to be approached with care, since Whyte is not proposing a general or universal experience of time but rather describing an experience and practice specific to Indigenous communities. Yet in urging non-Indigenous allies to take responsibility for their ancestral fantasies, Whyte suggests an obligation of spiraling temporal justice that extends to settlers as well at intergenerational scales. At the scale of elemental time, Library of Water expresses our predicament in the geological now by inviting us to register the links of memory that bind the glacial past to the far future, and to work with other futures on the basis of the inestimable present. ${ }^{11}$

\section{REFERENCES}

Artangel. 2007. "Vatnasafn/Library of Water." https://www.artangel.org.uk/project/ library-of-water/.

Benjamin, Andrew. 2017. "The World in Ruins: Heidegger, Poussin, Kiefer." Journal of Aesthetics and Phenomenology 4 (2): 101-23.

Berry, Wendell. 2015. Our Only World: Ten Essays. Berkeley, CA: Counterpoint Press.

Brady, Emily. 2013. The Sublime in Modern Philosophy: Aesthetics, Ethics, and Nature. Cambridge, MA: Cambridge University Press.

\footnotetext{
11 A longer version of this essay was presented at the 2019 Collegium Phaenomenologicum, and the author thanks the participants for their discussion and suggestions. An earlier version of portions of this essay appeared in Toadvine 2020, which addresses in more detail the temporality of apocalyptic narratives in popular climate change rhetoric.
} 
Brummett, Barry. 1984. "Premillenial Apocalyptic as a Rhetorical Genre." Central States Speech fournal 35 (2): 84-93.

Buell, Frederick. 2010. "A Short History of Environmental Apocalypse." In Future Ethics: Climate Change and Apocalyptic Imagination, edited by Stefan Skrimshire, 13-36. London: Bloomsbury.

Butler, Judith. 2009. "Critique, Dissent, Disciplinarity.” Critical Inquiry 35 (4): 773-95.

Collings, David. 2014. Stolen Future, Broken Present: The Human Significance of Climate Change. Ann Arbor, MI: Open Humanities Press.

Derrida, Jacques. 2007. Psyche: Inventions of the Other, Volume 1. Edited by Peggy Kamuf and Elizabeth Rottenberg. Stanford, CA: Stanford University Press.

Foust, Christina R. and William O'Shannon Murphy. 2009. "Revealing and Reframing Apocalyptic Tragedy in Global Warming Discourse." Environmental Communication 3 (2): 151-67.

Greenpeace International. 2009. "Horsemen of the Apocalypse Descend on Copenhagen." Scoop Independent News, December 16. http://www.scoop.co.nz/stories/WO0912/ S00466.htm

Gross, Lawrence W. 2014. Anishinaabe Ways of Knowing and Being. New York: Routledge.

Haller, Albrecht von. 2002. "Unvollkommenes Gedicht über die Ewigkeit / Uncompleted Poem on Eternity." Translated by Arnulf Zweig. The Philosophical Forum 33 (3): 30411.

Horne, Gerald. 2018. The Apocalypse of Settler Colonialism: The Roots of Slavery, White Supremacy, and Capitalism in Seventeenth-Century North America and the Caribbean. New York: Monthly Review Press.

Hume, David. 2007. A Treatise of Human Nature, Volume 1. Edited by David Fate Norton and Mary J. Norton. Oxford: Oxford University Press.

Hutton, James. 1788. Theory of the Earth. Edinburgh: Royal Society of Edinburgh.

Jones, Ben. 2017. "The Challenges of Ideal Theory and Appeal of Secular Apocalyptic Thought." European fournal of Political Theory (Online First): 1-24. 
Jordans, Frank and Monika Scislowska. 2018. "Climate Change is 'Most Important Issue We Face,' UN Chief Says," PBS, December 3. https://www.pbs.org/newshour/ world/climate-change-is-most-important-issue-we-face-un-chief-says.

Kant, Immanuel. 1987. The Critique of Judgment. Translated by Werner S. Pluhar. Indianapolis, IN: Hackett Publishing.

- 1996. Religion and Rational Theology. Translated and edited by Allen W. Wood and George di Giovanni. Cambridge: Cambridge University Press.

—. 2007. Anthropology, History and Education. Edited by Robert B. Louden and Günter Zöller. Cambridge: Cambridge University Press.

Killingsworth, M. Jimmie and Jacqueline S. Palmer. 1996. "Millenial Ecology: The Apocalyptic Narrative from Silent Spring to Global Warming." In Green Culture: Environmental Rhetoric in Contemporary America, edited by Carl G. Herndl and Stuart C. Brown, 21-45. Madison: University of Wisconsin Press.

Klein, Naomi. 2014. This Changes Everything: Capitalism vs. The Climate. New York: Simon \& Schuster.

Nancy, Jean-Luc. 1997. The Sense of the World. Translated by Jeffrey S. Librett. Minneapolis: University of Minnesota Press.

- 2015. After Fukushima: The Equivalence of Catastrophes. Translated by Charlotte Mandell. New York: Fordham University Press.

— 2017. The Possibility of a World: Conversations with Pierre-Philippe Jandin. Translated by Travis Holloway and Flor Méchain. New York: Fordham University Press.

Nordhaus, Ted and Michael Shellenberger. 2007. Break Through: From the Death of Environmentalism to the Politics of Possibility. Boston: Houghton Mifflin Harcourt.

Playfair, John. 1822. The Works of Fohn Playfair, Esq., Volume 4. Edinburgh: A. Constable \& Co.

Royal Society of Edinburgh. 1788. Transactions of the Royal Society of Edinburgh . Edinburgh: Royal Society of Edinburgh. https://archive.org/details/transactionsofro01roya/ page/n7/mode/2up.

Serres, Michel. 2018. The Incandescent. Translated by Randolph Burks. London: Bloomsbury.

Serres, Michel and Bruno Latour. 1995. Conversations on Science, Culture, and Time. Translated by Roxanne Lapidus. Ann Arbor: University of Michigan Press. 
Skrimshire, Stefan. 2014. "Climate Change and Apocalyptic Faith." WIREs Climate Change $5(2): 233-46$.

Toadvine, Ted. 2014. "The Elemental Past." Research in Phenomenology 44 (2): 262-79.

— 2020. "Climate Apocalypticism and the Temporal Sublime." In Environmental Ethics: Cross-Cultural Explorations, edited by Monika Kirloskar-Steinbach and Mădălina Diaconu, 115-31. Freiburg: Verlag Karl Alber.

United Nations, n.d. "Climate Change." Accesesd June 1, 2020. https://web.archive.org/ web/20190525005813/https://www.un.org/en/sections/issues-depth/climatechange/.

Whyte, Kyle Powys. 2018. "Indigenous Science (Fiction) for the Anthropocene: Ancestral Dystopias and Fantasies of Climate Change Crises." Environment and Planning E: Nature and Space 1 (1-2): 224-42.

Wood, David. 2017. "Temporal Phronesis in the Anthropocene." Research in Phenomenology 47 (2): $220-27$.

The World Bank. 2018. "Nearly Half the World Lives on Less than $\$ 5.50$ a Day," October 17. https://www.worldbank.org/en/news/press-release/2018/10/17/nearly-halfthe-world-lives-on-less-than-550-a-day. 